\title{
Assessing public interest towards renewable wind energy using Google Trends
}

\author{
Alexandra Perju-Mitran ${ }^{1, *}$, Daniela Zirra ${ }^{1}$ and Raul Mitran ${ }^{2}$ \\ 1 Romanian-American University; perju.alexandra@profesor.rau.ro, zirra.daniela@profesor.rau.ro \\ 2 Affiliation 2; raul.mitran@gmail.com \\ * Correspondence: perju.alexandra@profesor.rau.ro
}

\begin{abstract}
The public interest towards renewable and clean energy is an important part of shaping consumer behavior and policy towards these topics. A "big data" approach towards assessing the public interest for various topics consists in using freely available search frequency data for the Google search engine, through the Google Trends service. The search data frequency can be used to assess public opinion for a variety of topics, such as medicine, climate change and environmental concerns, finance, and economics etc. A study of the public interest towards wind energy topics is reported here. Six Google search keywords ("Wind power", "Wind energy", "Offshore wind", "Wind farm", "Wind turbine" and "Wind generator") were investigated in the 2004-2020-time range. All keywords except "Offshore wind" show a steady decrease from a 2008 - 2010 maximum up to 2015 , followed by a period limited change in the $2015-2020$ range. The interest towards offshore wind topics follows a similar trend but increases in frequency starting from 2015 and reaches a maximum in 2018. Overall, the Google Trends data show a decrease of public interests towards most wind energy topics, with the exception of "Offshore wind", for English speaking users, in the 2004-2020-time range.
\end{abstract}

Keywords: consumer behavior, Google Trends, wind energy, public interest, environmental marketing.

\section{Introduction}

The transition from polluting fossil fuel to renewable energy is a major aspect of addressing climate change. A key parameter affecting both public policy and consumer behavior towards renewable energy is public opinion [1]. Along with the daunting scale of climate change and coal as the largest source of global temperature increase [2], recent research illustrates the possibility of substantial reductions in the emissions of greenhouse gases at global scale and significant reductions in the amount of temperature increase by achieving expansion of wind energy installed capacity [3].

Recently, internet search engine volume and frequency of specific keywords has been shown to be strongly correlated with public interest and participation in political issues [4].

Many studies have used available Google search data to measure the interest towards numerous topics, including the environment [5], disease outbreaks [6], finance [7], energy prices [8], precious metals prices [9] etc.

The use of Google search data for assessing public opinion is validated by the fact that it has the same accuracy as surveys [10].

Of particular note is public interest towards environmental and conservation concerns, which was shown to decrease for most topics, with the exception of climate change [5]. Even though it would be expected that the public interest towards renewable energy is increasing, as it is an important component of addressing global warming, we have recently shown that it is not the case for solar energy [11]. 
The "Green energy" search keyword was also shown to have a slight decrease in frequency starting from 2010 [12]. The interest towards renewable energy for US household energy consumers was assessed using Google Trends [13].

The study found that the "renewable" Google keyword has a strong and negative correlation with energy consumption, showing that interest in renewable energy is a major factor affecting electricity use at individual household level.

Here, the public interest towards wind energy is assessed by using Google search frequency, freely provided through the Google Trends service. This study looks at English search keywords associated with wind energy and it encompasses the 2004-2020-time span. It is worth noting that the public interest towards wind energy concerns has not been studied using Google search data thus far.

\section{Methods}

Search query data was freely obtained from the Google Trends website (trends.google.com). Each time series contains monthly values from 2004 to present (January 2021) indicating the popularity of a given search time. The search data was obtained using the "Worldwide" setting, which corresponds to the total Google search volume.

The data is scaled with respect to total searches performed in a given location and time interval [14]. Furthermore, the data points belonging to a time series are normalized between 0 and 100 with respect to the highest point.

Each data point provided by the service corresponds to a week of search data. Google Trends does not report data below a minimum number of monthly searches (e.g., 50). It is important to use multiple related keywords to assess the interest towards a given topic, since keyword popularity might change over time or a specific term might be used for unrelated topics $[5,10]$.

In the present study, six keywords were selected in order to investigate the public interest towards wind energy: "Wind power", "Wind energy", "Offshore wind", "Wind farm", "Wind turbine" and "Wind generator".

In order to assess the consumer-related interest towards small-scale wind power installations, related search keywords containing "small", "home", "for home", "kit" or "diy" queries were also included.

Finally, it is worth noting that although Google Trends data is both scaled and normalized, it does not consider changes in the language preference of the users. To account for this effect, the usage of 3 very common English words, "the", "of", "and", was also investigated and used to create a baseline.

\section{Results and discussion}

The data provided by Google Trends can be used to assess the public interest towards a specific topic, since it is proportional to the search frequency for a given keyword during a specific time range.

Even though the data is normalized between 0 and 100, Google Trends provides an option to compare up to five keywords on the same scale: i.e., all five-time series are normalized relative to the highest data value present.

The Google Trends data therefore considers changes in search volume. To account for the changes in user language preference, a baseline consisting of common English words can be used (Figure 1).

This baseline was constructed as the sum of the "The", "Of" and "And" keyword values, renormalized between 0 and 100 (Figure 1). All three common English keywords as well as their sum exhibit a similar behavior, with maximum values at the beginning of the investigated time range, followed by decline up to 2008 and relatively constant levels since then. This data can be understood as an increase in non-English users from 2004 to 2008 , followed by a relatively stable fraction of these users since. 
All baseline data shows monthly variations which follow the same trends. Local minima of search volumes can be noticed for the summer months (June, July, August) and December, which can be correlated with the traditional summer and winter vacations and holidays in the northern hemisphere.
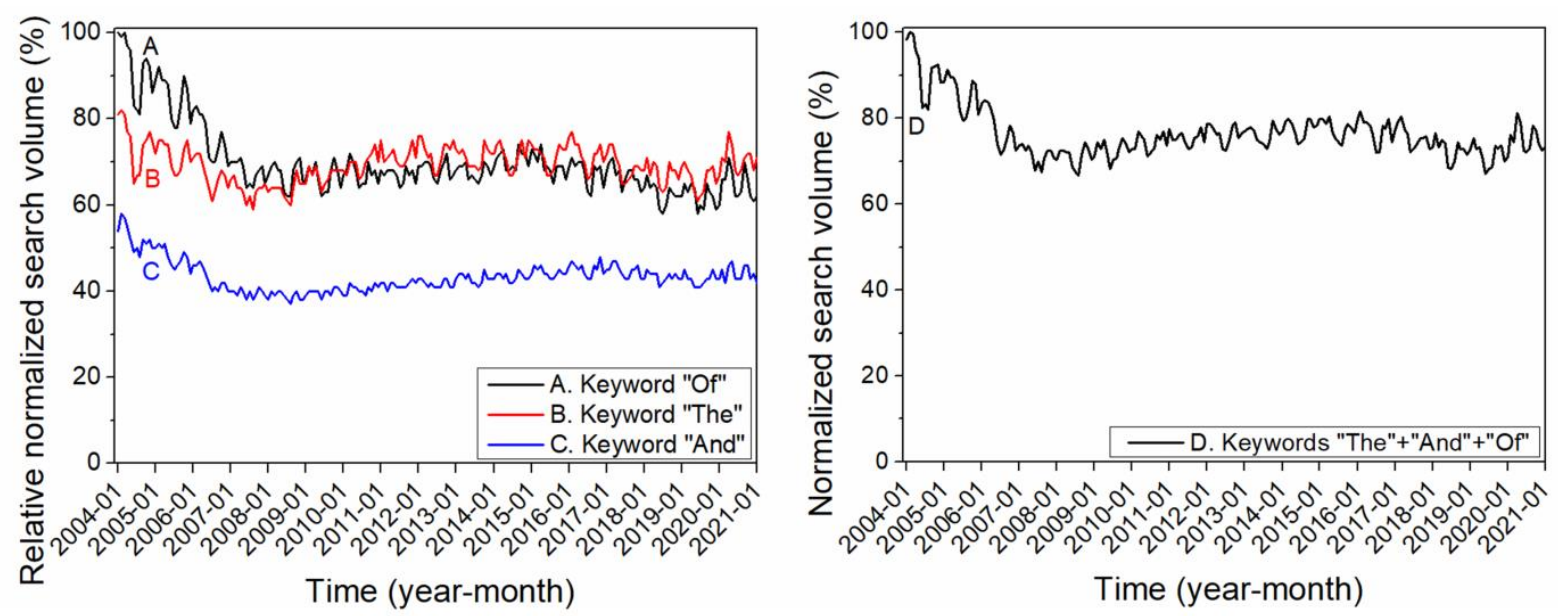

Figure 1. Normalized Google search data of common English words A) “Of", B) "The", C) "And" and D) the baseline constructed by renormalization of their sum.

Source: Baseline calculations

The time series corresponding to the six keywords associated with wind energy are presented in Figure 2. Each time series is normalized with respect to its maximum value, but not with respect to the changes in Google search engine use.

All keywords except "Offshore wind" show a similar pattern, with maximum values in the 2008-2010-time range. "Offshore wind" is an exception here, having a local maximum value in 2010-2011.
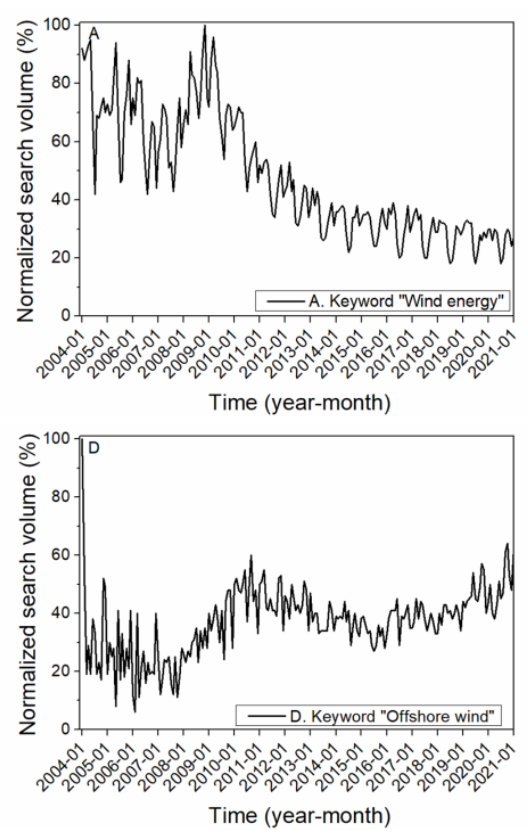
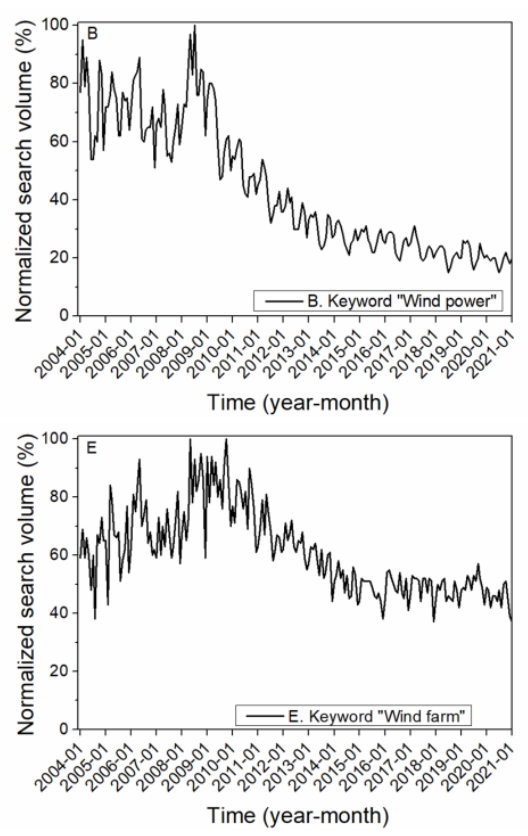
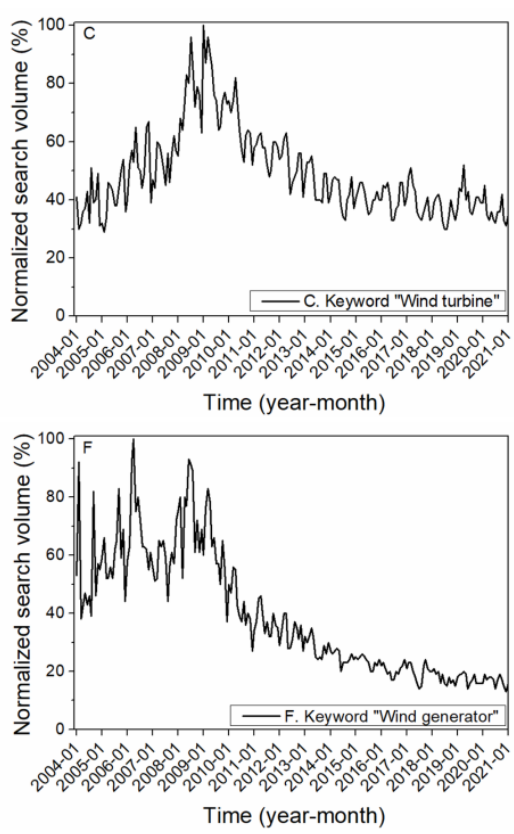

Figure 2. Google search data for six wind energy keywords - The data does not consider changes in language use.

Source: Baseline calculations 
All six keywords exhibit decreasing frequency after their period of maximum values. Again, "offshore wind" search term is an exception. While the interest for this term decreased after its 2011 local maximum, the frequency of the keyword has increased from 2015 to 2020.

The effect of changes in search engine use is considered in Figure 3.
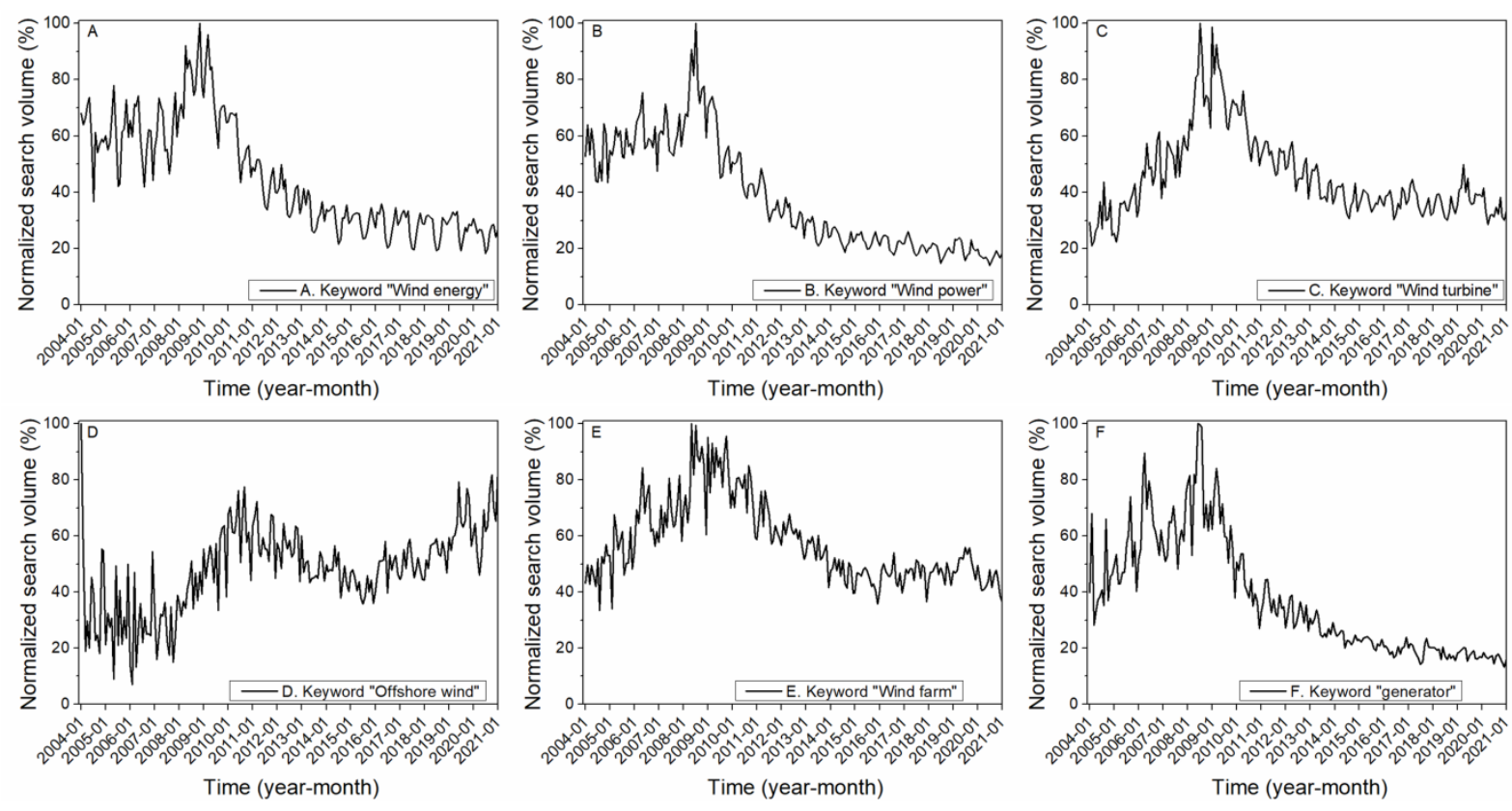

Figure 3. Google search data for six wind energy keywords, renormalized with respect to changes to Google search engine use, such as English language preference.

Source: Baseline calculations

The time series for each keyword were constructed by dividing each data point to the baseline value for the same month, followed by renormalization. A similar behavior can be noticed for the renormalized time series, showing that changes over time in Google search engine use to not qualitatively affect the results.

Thus, all keywords present a period of maximum frequency in the 2008-2011-time range, followed by gradual decline.

The only exception is again "Offshore wind", for which the search frequency increases starting with 2016. This could be explained by the fact that this technology is relatively new, with the first operating offshore wind power plant being installed in 1991 [15].

Google search data shows a significant month-to-month and seasonal variations, which are similar each year. This effect can even be noticed for the baseline common English words.

Yearly values were computed for each keyword, using the baseline corrected values. The annual values show the same trend as the month-to-month data, with maximum values in 2008 or 2009 for most keywords and in 2010 for "Offshore wind" (Figure 4).

All keywords decrease in search frequency from their maxima during the 20092014-time range. Four out of six keywords maintain relatively stable search frequency in the following 2015-2020-time interval, showing a slight upward trend starting from 2018.

However, both "Offshore wind" and "Wind farm" search terms increase in the 2015-2020-time interval, with the "Offshore wind" keyword having 2\% more search volume in 2019 as compared with the local maximum of 2010. 


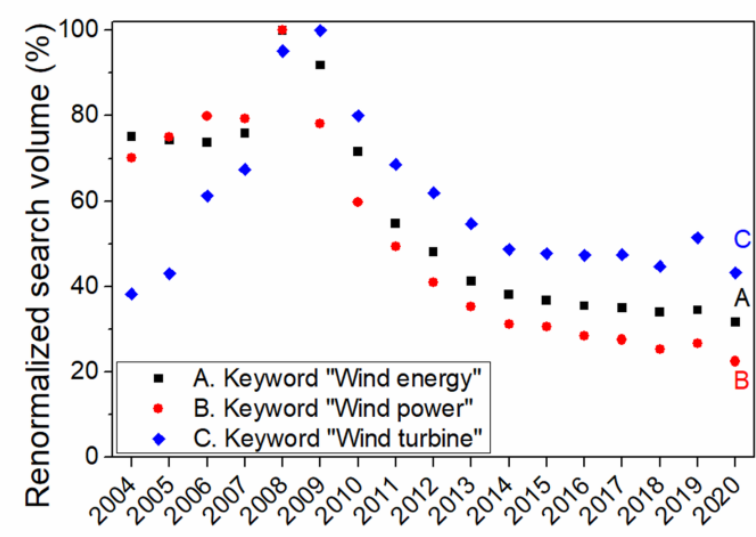

Time (year)

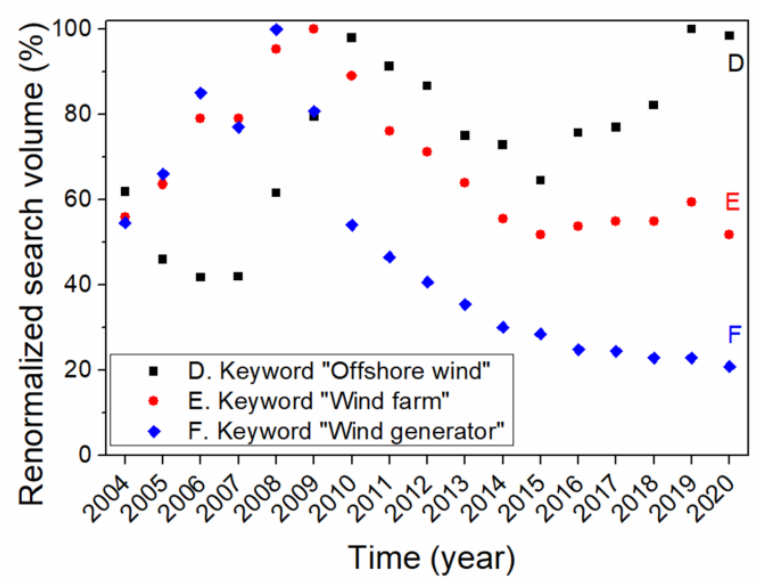

Figure 4. Annual search volume of the six wind energy keywords Source: Baseline calculations

In order to better understand the changes in Google search volume for the wind energy keywords, it can be useful to look at installed wind energy capacity. The annual installed capacity for onshore and offshore wind generators, as well as the total annual installed capacity was obtained from the Global Wind Energy Council, which publishes yearly data (Figure 5) [16].
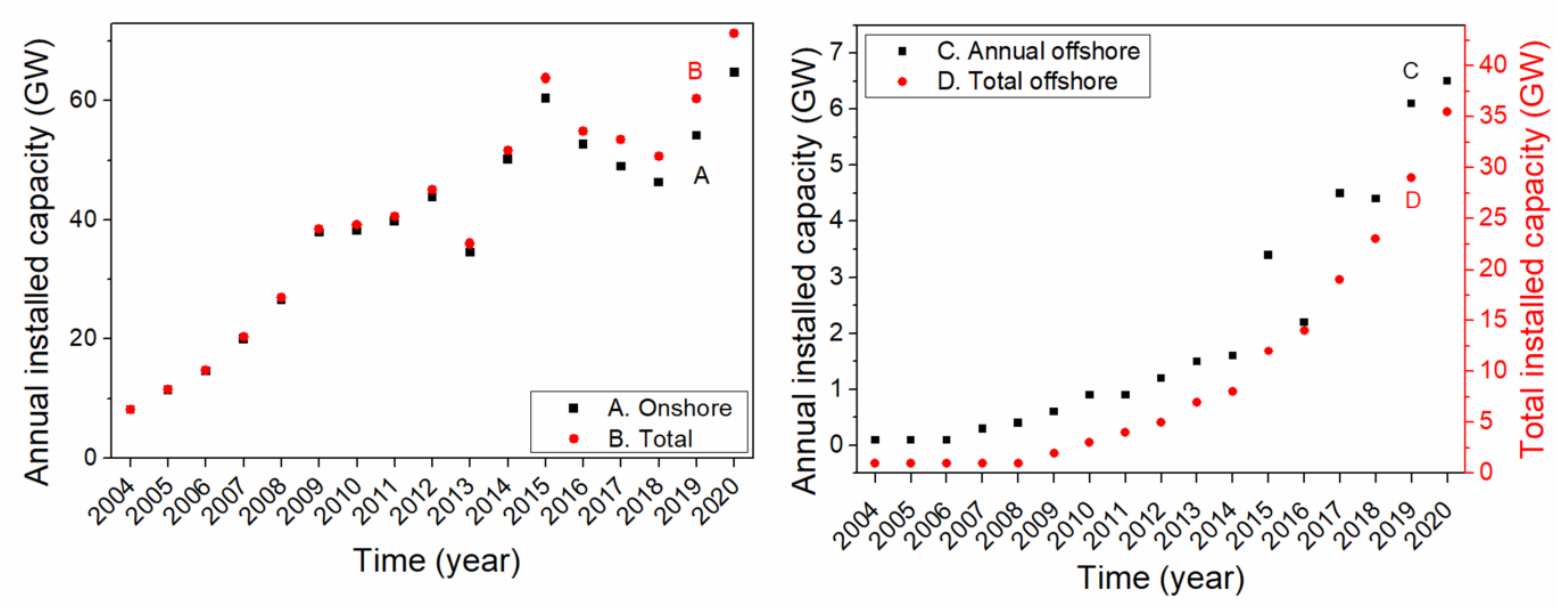

Figure 5. Annual installed capacity of A) onshore and B) total wind capacity, C) annual installed offshore wind capacity and D) total installed offshore wind capacity.

Source: Annual installed wind capacity calculations

The annually installed total and onshore wind capacity (Figure 5 A, B) follows the same trend, as onshore wind generators make up $~ 90 \%$ of total installed wind capacity.

Three distinct time ranges can be constructed based on the rate of newly installed wind capacity: a) $2004-2009$ is a period of increased wind capacity, with an average rate of increase of $36 \pm 6 \%$ per year for both onshore and total capacity; b) $2010-2018$ marks a period of slower growth and higher variability, with an average change of $4 \pm 19 \%$ per year, and c) 2018 - 2020 shows the resumption of annual installed capacity growth at a rate of $18 \pm 2 \%$ per year.

Interestingly, these three distinct regimes of installed capacity change for both onshore and total wind energy are reflected in the Google search volume for the six keywords. Offshore wind is a newer technology, reaching 2 GW of total installed capacity only in 2009. 
Two distinct regimes of annual installed offshore capacity can be noticed (Figure 5 C): a period of linear growth at $0.7 \pm 0.5 \mathrm{GW}$ per year during 2006-2014 and a regime of faster increase between 2014 and 2020, at $4.1 \pm 1.8 \mathrm{GW}$ per year. The period of faster growth roughly corresponds to the increase of search frequency for the "Offshore wind" and "Wind farm" keywords (Figure 4 D, E) starting from 2015.

The relative frequency of the maximum values for each keyword was computed over the 2004-2020-time range (Figure 6 A). "Wind energy", "Wind power" and "Wind turbine" make up most searches related to the wind energy topic, having $28.0 \%, 26.0 \%$ and $25.2 \%$ of the total search volume, respectively.

The "Offshore wind" keyword has only $3.2 \%$ of the total search volume, which is comparable to the fraction of installed offshore wind capacity from the total installed wind capacity, at $4.9 \%$. The total weighted sum of the six keywords was also computed (Figure 4 B). Since the keywords with the largest decrease from 2004 to 2020 are the most frequent, the aggregate sum follows their behavior.

A 2008 maximum can be noticed for the aggregate sum, followed by gradual decline up to 2016. Thus, most the individual keywords and their aggregate sum show the decline in search frequency for wind energy topics from their 2008 maximum, indicating decreased public interest towards this topic. The sole exception is represented by the "Offshore wind" keyword, which has garnered increased interest and search volume starting from 2015.
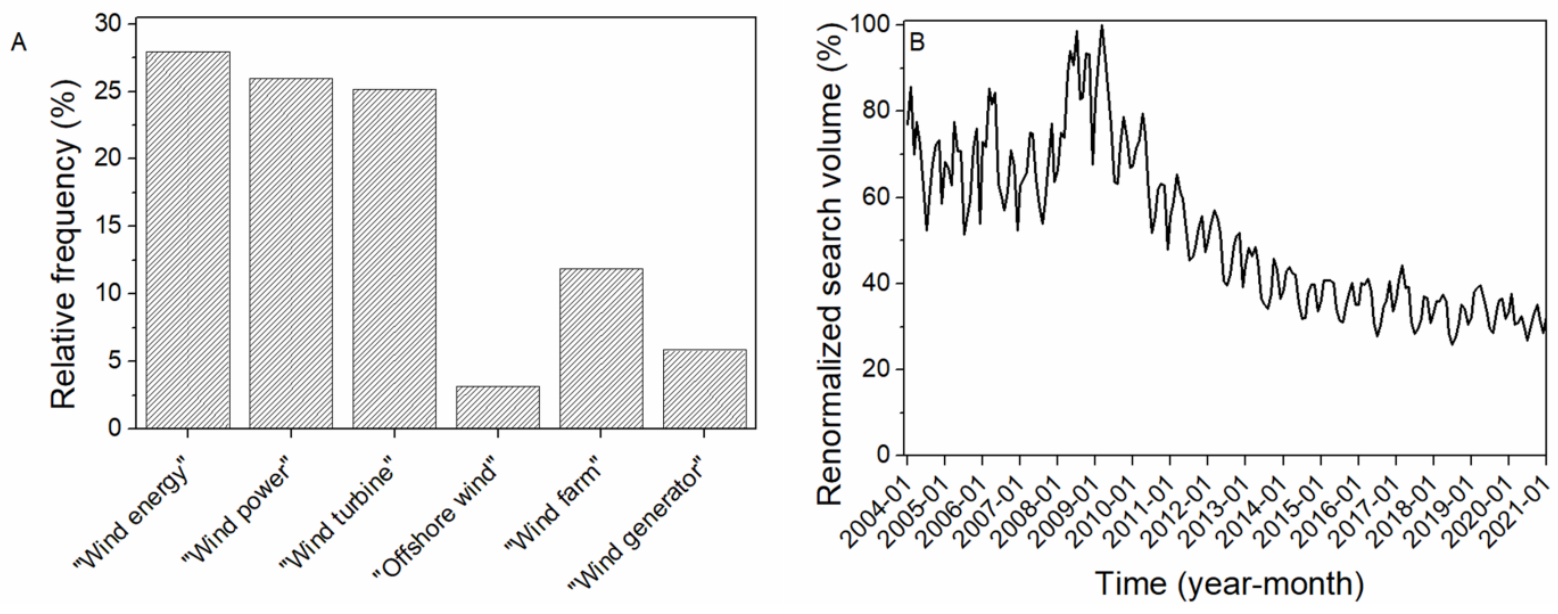

Figure 6. A) Relative frequency of the six keywords, and B) The normalized sum of the six wind energy keywords.

Source: Keyword frequency normalization calculations

Google Trends data also contain information about the geographical distribution of the search frequency (Table 1). Even though the data is biased towards English speaking countries [17], the interest towards wind energy spans the globe, with both developed and developing countries occupying top 10 positions.

The data shows a global interest towards wind energy. As expected, countries with high wind potential (e.g., Ireland, Denmark, UK, New Zealand etc.) occupy top 10 search positions for multiple wind energy keywords.

We have recently investigated the public interest towards solar energy using the same methodology and found that while the interest towards large-scale solar installations is decreasing, the interest towards small-scale solar energy is increasing (Perju-Mitran \&. Mitran, 2018).

In order to check if a similar trend is present for wind energy, we have obtained the data for composite keywords also containing the "small", "home", "for home", "kit" or "diy" search terms (Figure 5). 
Table 1. Geographical distribution of the top 10 countries for each search keyword - Numbers in parenthesis represent the search percentage for each country.

\begin{tabular}{|c|c|c|c|c|c|}
\hline Wind energy & Wind power & Wind turbine & Offshore wind & Wind farm & Wind generator \\
\hline Ethiopia (100\%) & $\begin{array}{c}\text { Denmark } \\
(100 \%)\end{array}$ & Ireland $(100 \%)$ & $\begin{array}{c}\text { Denmark } \\
(100 \%)\end{array}$ & Ireland $(100 \%)$ & $\begin{array}{c}\text { Australia } \\
(100 \%)\end{array}$ \\
\hline $\begin{array}{c}\text { Trinidad \& } \\
\text { Tobago (89\%) }\end{array}$ & Ethiopia (71\%) & Jamaica $(79 \%)$ & Norway (79\%) & $\begin{array}{c}\text { United } \\
\text { Kingdom } \\
(72 \%) \\
\end{array}$ & $\begin{array}{c}\text { New Zealand } \\
(92 \%)\end{array}$ \\
\hline Jamaica $(73 \%)$ & Australia (52\%) & $\begin{array}{l}\text { United Kingdom } \\
\qquad(79 \%)\end{array}$ & St. Helena $(73 \%)$ & $\begin{array}{c}\text { Australia } \\
(68 \%)\end{array}$ & $\begin{array}{c}\text { South Africa } \\
\qquad(82 \%)\end{array}$ \\
\hline Ireland $(68 \%)$ & Canada (50\%) & $\begin{array}{c}\text { New Zealand } \\
(73 \%)\end{array}$ & $\begin{array}{l}\text { United Kingdom } \\
\qquad(55 \%)\end{array}$ & Jamaica (57\%) & Ireland (73\%) \\
\hline $\begin{array}{c}\text { South Africa } \\
(54 \%)\end{array}$ & Kenya (48\%) & Denmark (63\%) & Ireland (38\%) & $\begin{array}{c}\text { New Zealand } \\
(55 \%)\end{array}$ & Canada $(70 \%)$ \\
\hline India $(50 \%)$ & $\begin{array}{c}\text { New Zealand } \\
(47 \%)\end{array}$ & Australia (60\%) & $\begin{array}{c}\text { Netherlands } \\
(36 \%)\end{array}$ & $\begin{array}{c}\text { St. Helena } \\
(49 \%)\end{array}$ & $\begin{array}{l}\text { United States } \\
\qquad(67 \%)\end{array}$ \\
\hline Australia (50\%) & $\begin{array}{l}\text { United Kingdom } \\
\qquad(43 \%)\end{array}$ & Canada (58\%) & Singapore (28\%) & $\begin{array}{c}\text { South Africa } \\
\qquad(35 \%)\end{array}$ & Philippines (55\%) \\
\hline Canada (47\%) & Sri Lanka (42\%) & $\begin{array}{c}\text { South Africa } \\
\qquad(55 \%)\end{array}$ & South Korea $(27 \%)$ & $\begin{array}{c}\text { Denmark } \\
(33 \%)\end{array}$ & $\begin{array}{c}\text { United Kingdom } \\
\qquad(52 \%)\end{array}$ \\
\hline $\begin{array}{c}\text { United States } \\
(45 \%)\end{array}$ & $\begin{array}{c}\text { South Africa } \\
(40 \%)\end{array}$ & $\begin{array}{c}\text { United States } \\
(54 \%)\end{array}$ & Belgium (23\%) & Canada (26\%) & Greece (51\%) \\
\hline $\begin{array}{l}\text { United Kingdom } \\
\qquad(41 \%)\end{array}$ & Ireland (39\%) & Singapore (41\%) & Germany (20\%) & $\begin{array}{c}\text { United States } \\
\qquad(22 \%)\end{array}$ & Norway (43\%) \\
\hline
\end{tabular}

Source: trends.google.com

Unlike solar energy, the keywords related to small-scale wind power show a similar trend with their parent keywords, decreasing after a 2008-2010 maximum (Figure 7).

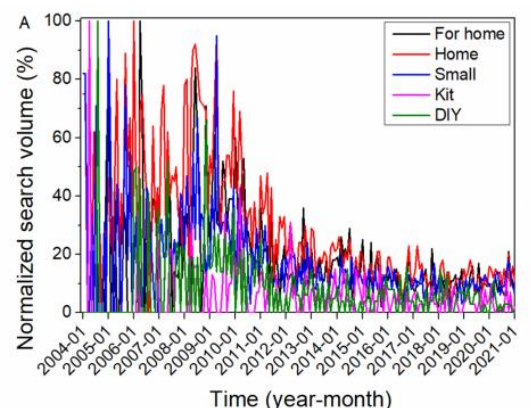

Time (year-month)

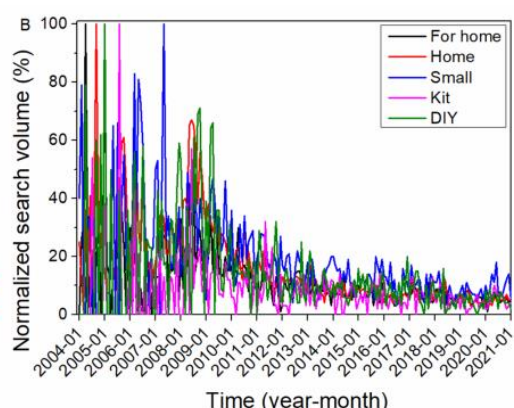

Time (year-month)

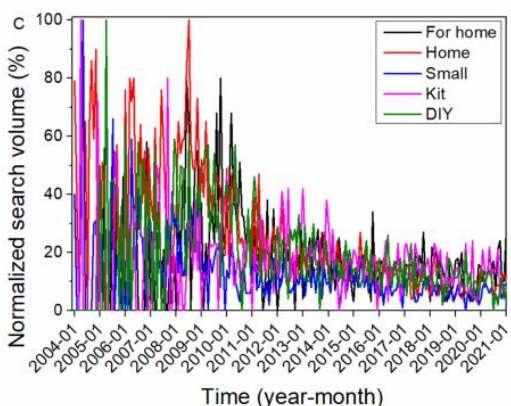

Time (year-month)

Figure 7. Google search data for selected keywords containing terms related to small-scale wind power use for the A) "Wind energy", B) "Wind power" and C) "Wind generator" keywords Source: trends.google.com

During the investigated timeline, the highest overall interest towards keywords related to small-scale wind power is shown slightly by the "Wind generator" keyword. 


\section{Conclusions}

The public interest towards wind energy was assessed Google search data provided by the Google Trends service, in the 2004-2020-time range. The novelty brought by the present study lies first in using a novel method towards assessing public interest towards such a topic as wind energy, towards which there have been rapidly evolving attempts in expanding penetration, in the context of global aspirations, and regional policies.

Six English search engine keywords related to wind energy were investigated. All keywords related to onshore wind power follow the same pattern, with a period of increasing frequency reaching maximum values in 2008-2011, followed by decline up to 2017. Only the "Offshore wind" keyword shows an increase in search frequency from 2015 onwards, reaching its maximum value in 2018. The same results are valid when correcting for changes in the search engine's language preference.

As the investigated keywords are in English, the geographical distribution of search frequencies is biased towards English speaking countries with high internet connectivity. Nonetheless, the results show global interest towards wind energy topics from both developed and developing countries.

Public interest towards a given topic influences both consumer behaviour and public policy. Even though the global installed wind power has increased between 2004 and 2020, our results show that the public interest towards this topic has decreased, having lower overall values in 2020 than in 2004. The only exception is the "offshore wind" search keyword, which has reached in maximum value in 2018. However, the search volume for this specific keyword in 2018 is only $2 \%$ higher than in 2010 . The increased public interest towards offshore wind power can be understood through the fact that offshore wind technology is newer and that installed offshore capacity has increased drastically in the 2010 - 2020 decade. This suggests that more action must be undertaken to raise public awareness and support towards renewable energy such as wind.

Future studies of this type with the potential to bring added value to our research topic may be directed towards comparisons between wind and other renewable energy topics and their respective keywords.

Author Contributions: Conceptualization, A.P.-M. and R.M.; methodology, R.M.; validation, A.P-M., D.Z. and R.M.; formal analysis, D.Z.; investigation, A.P.-M.; data curation, R.M.; writing-original draft preparation, A.P.-M. and R.M.; writing-review and editing, D.Z.; visualization, R.M.; supervision, A.P.-M. All authors have read and agreed to the published version of the manuscript.

Funding: This research received no external funding.

Data Availability Statement: The raw/processed data required to reproduce these findings can be obtained from the authors upon reasonable request.

Conflicts of Interest: The authors declare no conflict of interest. 


\section{References}

1. Page, B. I., \& Shapiro, R. Y. Effects of public opinion on policy. American political science review 1983, 77(1), 175-190.

2. IEA (2019). Global Energy \& CO2 Status Report. IEA: Paris, France, 2019; p. $29 . \quad$ Available on: https://www.iea.org/reports/global-energy-co2-status-report-2019, (accessed on 2 October 2021).

3. Barthelmie, R. J., \& Pryor, S. C. Climate change mitigation potential of wind energy. Climate 2021, 9(9), 136.

4. Reilly, S., Richey, S., \& Taylor, J. B. Using Google search data for state politics research: an empirical validity test using roll-off data. State Politics \& Policy Quarterly 2012, 12(2), 146-159.

5. McCallum, M. L., \& Bury, G. W. Google search patterns suggest declining interest in the environment. Biodiversity and conservation 2013, 22(6), 1355-1367.

6. Carneiro, H. A., \& Mylonakis, E. Google trends: a web-based tool for real-time surveillance of disease outbreaks. Clinical infectious diseases 2009, 49(10), 1557-1564.

7. Kristoufek, L. Power-law correlations in finance-related Google searches, and their cross-correlations with volatility and traded volume: Evidence from the Dow Jones Industrial components. Physica A: Statistical Mechanics and its Applications 2015, 428, 194-205.

8. Afkhami, M., Cormack, L., \& Ghoddusi, H. Google search keywords that best predict energy price volatility. Energy Economics 2017, 67, 17-27.

9. Salisu, A. A., Ogbonna, A. E., \& Adewuyi, A. Google trends and the predictability of precious metals. Resources Policy 2020, 65, 101542.

10. Zhu, J., Wang, X., Qin, J., \& Wu, L. Assessing public opinion trends based on user search queries: validity, reliability, and practicality. The Annual Conf. of the World Association for Public Opinion Research 2012, 1-7.

11. Perju-Mitran, A., \& Mitran, R. A. Assessing Public Opinion on Solar Energy Topics Using Google Trends. Journal of Information Systems \& Operations Management 2018, 153-162.

12. Mavragani, A., \& Tsagarakis, K. P. ‘Clean energy' vs. 'Green energy': Quantifying the online interest in USA \& Australia. Bulgarian Chemical Communications 2016, 48, 248-253.

13. Park, S., \& Kim, J. The effect of interest in renewable energy on US household electricity consumption: An analysis using Google Trends data. Renewable energy 2018, 127, 1004-1010.

14. McCallum, M. L., \& Bury, G. W. Public interest in the environment is falling: a response to Ficetola (2013). Biodiversity and conservation 2014, 23(4), 1057-1062.

15. Snyder, B., \& Kaiser, M. J. Ecological and economic cost-benefit analysis of offshore wind energy. Renewable Energy 2009, 34(6), 1567-1578.

16. Global Wind Energy Council, (2019). A.M. Update, Global wind report. Available on: https://gwec.net/global-wind-report-2019/, (accessed on 15 October 2021).

17. Al-Eroud, A. F., Al-Ramahi, M. A., Al-Kabi, M. N., Alsmadi, I. M., \& Al-Shawakfa, E. M. Evaluating Google queries based on language preferences. Journal of Information Science 2011, 37(3), 282-292. 